\title{
Fibroelastoma en el ventrículo izquierdo: un hallazgo muy poco frecuente
}

\author{
Laura Álvarez Roy ${ }^{1}$ \\ Isabel Ruíz Zamora' \\ Guillermo Pinillos Francia' \\ Pilar Portero Pérez ${ }^{1}$ \\ Omer Leal Fernández ${ }^{2}$ \\ Diego Sánchez Valenzuela ${ }^{2}$ \\ Ignacio Pérez-Moreiras López ${ }^{3}$ \\ Pedro María Azcárate Agüero ${ }^{1}$
}

${ }^{1}$ Hospital San Pedro de la Rioja, Logroño

${ }^{2}$ Clínica los Manzanos, Logroño;

${ }^{3}$ Policlínica Gipuzkoa, Donostia-San Sebastián

Enviado: 10/10/2021

Aceptado:05/11/2021.

Publicado: 15/12/2021

Citar como: Álvarez Roy L, Ruíz Zamora I, Pinillos Francia G, Portero Pérez P, Leal Fernández O, Sánchez Valenzuela D, Pérez-Moreiras López I, Azcárate Agüero PM. Fibroelastoma en el ventrículo izquierdo: un hallazgo muy poco frecuente. RETIC. 2021 (Diciembre); 4 (3): 32-34. doi: 10.37615/retic.v4n3a9

Cite this as: Álvarez Roy L, Ruíz Zamora I, Pinillos Francia G, Portero Pérez P, Leal Fernández O, Sánchez Valenzuela D, Pérez-Moreiras López I, Azcárate Agüero PM. Fibroelastoma in the left ventricle: a very rare finding. RETIC. 2021 (December); 4 (3): 32-34. doi: 10.37615/retic.v4n3a9

\section{RESUMEN}

La valoración de las masas cardíacas es un problema clínico relativamente frecuente para las técnicas de imagen cardíca. Presentamos el caso de una masa cardíaca con localización inusual en el que las técnicas de imagen permitieron orientar el diagnóstico, que como no puede ser de otro modo, se confirmó en la cirugía.

\section{ABSTRACT}

The evaluation of cardiac masses is a relatively frequent clinical problem for cardiac imaging techniques. We present the case of a cardiac mass with an unusual location in which imaging techniques made it possible to guide the diagnosis, which, how could it be otherwise, was confirmed in surgery.

\section{Presentación del caso}

Una mujer de 74 años con historia de HTA y dislipemia en tratamiento farmacológico, varices en ambas piernas y colecistectomía previa, es decir, sin grandes antecedentes de interés, acudió a consulta para valoración por presentar episodios de dolor torácico de perfil relativamente atípico. Se realizó un ecocardiograma en el que se encontró de forma inesperada una masa en el ventrículo izquierdo.

En el ecocardiograma transtorácico se apreció una masa muy móvil de aproximadamente $8 \times 7 \mathrm{~mm}$ de aspecto hiperecogénico, pediculada, aparentemente dependiente del papilar posterior y con un movimiento de balanceo amplio dentro de la cavidad del ventrículo izquierdo (Video 1). El estudio 3D confirmó la presencia de la masa y permitió comprobar su aspecto redondeado con un pedículo anclado en el papilar posterior (Video 2).
El siguiente paso en el estudio fue la resonancia magnética. En las imágenes de cine se apreció una masa móvil de $4 \times 5 \mathrm{~mm}$ anclada en el aparato subvalvular mitral (Video 3). En la imagen potenciada en T2 tenía aspecto hiperintenso. En la secuencia de perfusión la masa aparentemente no captaba contraste. Finalmente, en la imagen de realce precoz la masa aparecía con aspecto hipointenso pero se hizo hiperintensa en las imágenes de realce tardío. Con este comportamiento se planteó el diagnóstico de fibroelastoma papilar. Dado que se trataba de una masa de un tamaño ya bastante apreciable y un comportamiento muy móvil se consideró que el riesgo embólico era elevado y se indicó tratamiento quirúrgico

En la preparación de la cirugía se realizó una coronariografía que encontró enfermedad de un vaso con estenosis severa de la coronaria derecha media que se trató con angioplastia y el implante de un stent farmacoactivo. Se inició doble antiagregación con Aspirina y Clopidogrel y pocas semanas después se realizó la cirugía. La masa se pudo resecar sin problemas y el estudio de anatomía patológica confirmó el diagnóstico de un fibroelastoma papilar de $8 \mathrm{~mm}$ de diámetro 


\section{- Casos clínicos caso 06}

\section{Estudio por imagen}

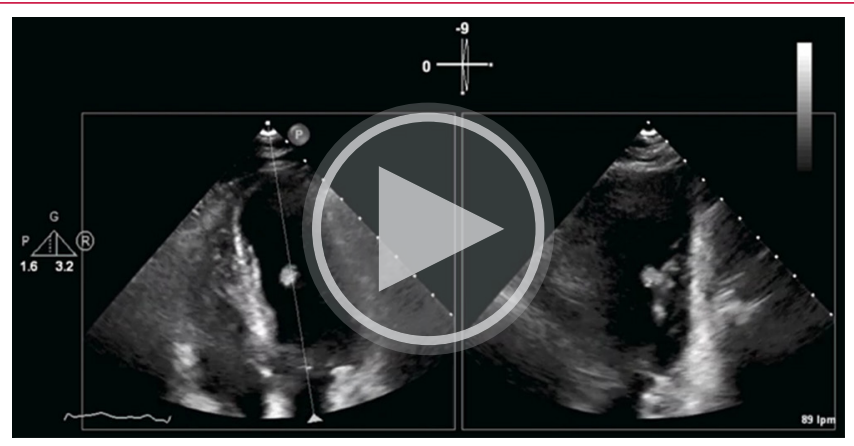

Vídeo 1. Ecocardiograma transtorácico. Esta imagen biplano nos muestra a la izquierda el plano apical de 4 cámaras y a la derecha el plano apical de dos cámaras. Llama mucho la atención una masa de buen tamaño de aspecto hiperecogénico y movimiento de balanceo amplio

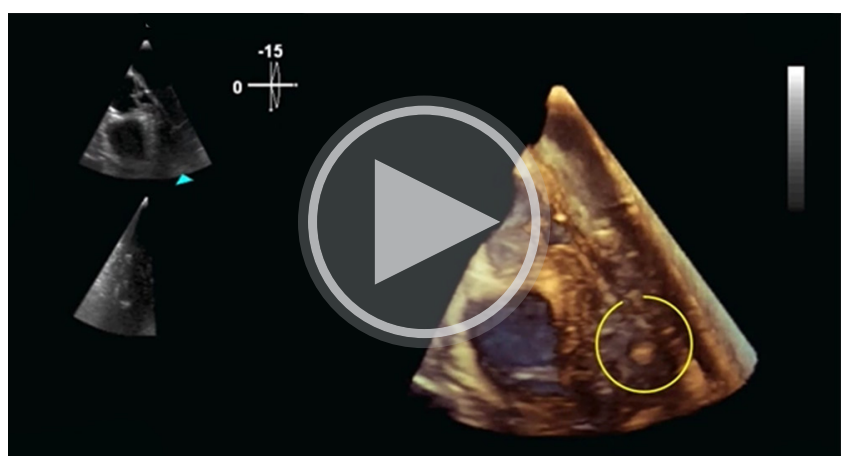

Vídeo 2. Ecocardiograma transesofágico 3D. La reconstrucción está orientada en el plano de $135^{\circ}$ que equivale al plano de tres cámaras. La imagen 3D hace muy evidente la masa, su morfología pediculada y su relación con el papilar posterior.

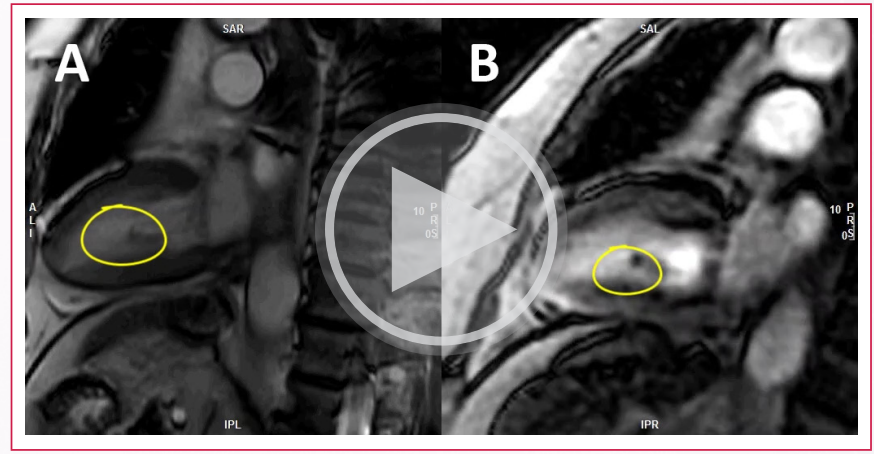

Vídeo 3. Resonancia magnética cardíca. En A se muestra la imagen de cine con la orientación del plano largo de dos cámaras y en B la imagen de perfusión. Se aprecia una pequeña masa irregular mal definida que no aumenta de intensidad de señal en la secuencia de perfusión de primer paso.

\section{Discusión}

El fibroelastoma papilar es el segundo tipo de tumor cardíaco primario más frecuente. El diagnóstico de sospecha es relativamente sencillo cuando tiene un aspecto típico y está localizado en el endocardio de las válvulas mitral y aórtica.

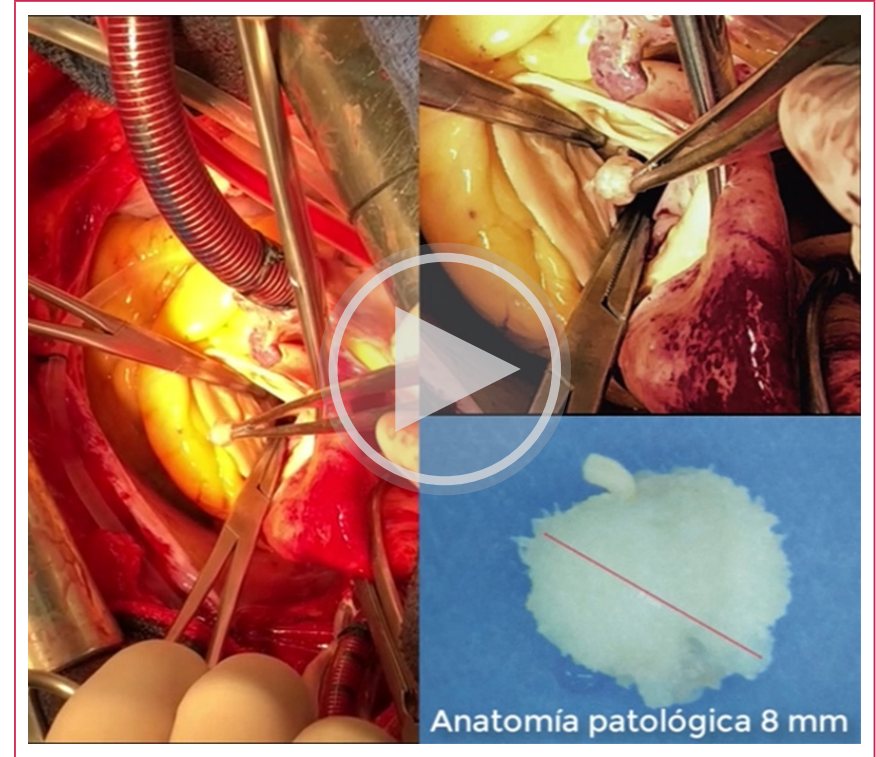

Vídeo 4. Hallazgos de la cirugía. La imagen muestra el momento en el que la pinza del cirujano saca la masa cardíaca. El detalle de la esquina corresponde al aspecto macroscópico de la pieza quirúrgica.

Sin embargo, ver uno localizado en el aparato subvalvular es excepcional ${ }^{1}$

La clínica es relativamente inespecífica. Lo más frecuente es que cursen de forma asintomática durante muchos años. Los síntomas aparecen en forma de fenómenos embólicos, incluyendo ictus, infarto o incluso la muerte súbita. El diagnóstico inicial se hace a través de las técnicas de imagen, habitualmente en el ecocardiograma. Como se trata de una lesión muy móvil de escaso tamaño puede ser muy difícil de localizar o de estudiar con otras técnicas de imagen como la resonancia magnética cardíaca. El tratamiento de elección es la cirugía, que se suele indicar ante el riesgo de que el tumor produzca fenómenos embólicos, especialmente si se trata de masas grandes de más de $1 \mathrm{~cm}$ o son muy móviles, ya que la movilidad parece ser el principal factor predictor de eventos.

En nuestra paciente es difícil atribuir las molestias torácicas que presentaba al fibroelastoma, que con mucha mayor probabilidad fue un hallazgo incidental. Sin embargo, el fibroelastoma fue la causa del cateterismo prequirúrgico que permitió resolver su problema clínico.

\section{Conclusión}

El fibroelastoma papilar es un tumor infrecuente que de forma excepcional puede estar localizado fuera de las válvulas cardiacas. Su aspecto típico y su comportamiento en el ecocardiograma y la RMN permiten orientar la sospecha diagnóstica. El tratamiento habitualmente es quirúrgico para evitar el riesgo de fenómenos embólicos.

\section{Ideas para recordar}

- El fibroelastoma papilar puede estar localizado de forma excepcional fuera de las válvulas.

- El endocardio del ventrículo izquierdo es la localización extravalvular más frecuente de los fibroelastomas

- La movilidad del tumor en pacientes con un fibroelastoma cardíaco es el principal factor predictor de fenómenos embólicos en el seguimiento. 


\section{Bibliografía}

1. Gowda RM, Khan IA, Nair CK, Mehta NJ, Vasavada BC, Sacchi TJ. Cardiac papillary fibroelastoma: A comprehensive analysis of 725 cases. Am Heart J. 2003;146:404-10
2. Sun JP, Asher CR, Yang XS, et al. Clinical and echocardiographic characteristics of papillary fibroelastomas: a retrospective and prospective study in 162 patients. Circulation. 2001;103:2687

3. O'Donnell DH, Abbara S, Chaithiraphan V, Yared K, Killeen RP, Cury RC, Dodd JD. Cardiac tumors: optimal cardiac MR sequences and spectrum of imaging appearances. AJR Am J Roentgenol 2009;193:377-87. 